\section{Assessment of the new investment limits for assets of Social Security Regimes for Public Servants established by Resolution CMN3,922/2010}

\author{
Alexandre Teixeira Damasceno ${ }^{1}$ \\ João Vinícius de França Carvalho ${ }^{2}$
}

\begin{abstract}
Purpose - To verify if the new investment limits for the Social Security Regimes for Public Servants (RPPSs) introduced by Resolution CMN 3,922/2010 enable the creation of investment portfolios with sufficient returns capable of reaching and exceeding these entities' actuarial goals.
\end{abstract}

Theoretical framework - The research was based on Modern Actuarial Risk Theory, whose main objective is to assess the long-term (in)solvency of insurance and social security entities.

Design/methodology/approach - An ALM model of non-linear stochastic optimization with mean-CVaR was used to build the efficient frontiers related to each type of governance level defined by the legislation. Then, it was verified whether these portfolios are sufficiently capable of offering the required and expected returns.

Findings - The results show that only governance levels III and IV would be able to build portfolios with the expected returns capable of reaching the actuarial goal. However, this was only possible at the maximum risk limit of the efficient frontier.

Research Practical \& Social implications - There is evidence of the need for the competent authorities to review the parameters of the investment limits, since adjustments to the RPPS investment legislation can bring social benefits, as they would avoid problematic situations of RPPS actuarial deficits that could put them at risk of not providing benefits to retirees.

Originality/value - This article is a pioneer in assessing the (in)adequacy of the normative allocation limits for RPPS guarantee assets, using an asset-only nonlinear optimization methodology.

Keywords - ALM Models; Social Security Regimes for Public Servants; Actuarial Goals; Actuarial Models; Investment Policies.

\section{Universidade de São Paulo, Departamento de Contabilidade e Atuária, São Paulo, Brazil}

2. Universidade de São Paulo, Departamento de Contabilidade e Atuária, São Paulo, Brazil

\section{How to cite:}

Damasceno, A. T.; Carvalho, J. V. F. (2021). Assessment of the new investment limits for assets of Social Security Regimes for Public Servants established by Resolution CMN 3,922/2010. Revista Brasileira de Gestâo de Negócios, 23(4), p.728-743.
Received on:

06/29/2020

Approved on:

$01 / 18 / 2021$

Responsible Editor:

Prof. Dr. Joelson Sampaio

\section{Evaluation process:}

Double Blind Review

\section{Reviewers:}

Elizabeth Borelli; Roberto Cazzari

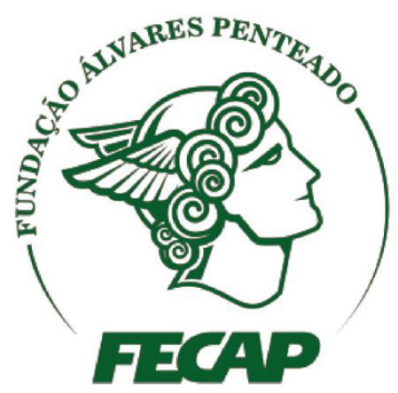

Revista Brasileira de Gestáo de Negócios

https://doi.org/10.7819/rbgn.v23i4.4128 


\section{Introduction}

The Social Security Regimes for Public Servants (RPPSs) is a system established within the scope of each federative entity - union, states, Federal District, and municipalities - that ensures that civil servants at least have retirement and pension for death benefits. Each RPPS has its own management responsible for organizing the social security of public servants. These can be both active public servants as well as those already receiving benefits (retirees) and pensioners, whose benefits are paid by the federative entity. The objectives of the main RPPSs are to administer and manage pension funds and to manage and operationalize the institution itself, including granting, paying, and maintaining benefits for participants.

In Brazil there are currently 2,216 RPPSs, which together have approximately BRL 277.33 billion (Brasil, 2017), approximately $4.07 \%$ of Brazil's GDP, of funds invested in guarantee assets. The National Monetary Council (CMN), through Resolutions 4,604/2017 and 4,695/2018, amended Resolution 3,922/2010, defining new limits for the application of RPPS funds. The period leading up to these changes was marked by numerous governance and interference problems that involved state-owned pension funds and the RPPSs, which were widely reported by the mediai. In light of this problematic environment, the new regulation introduced more rigid and restrictive investment rules for RPPSs, which may imply a significant reduction in the profitability of admissible portfolios.

According to modified Resolution 3,922/2010, there are four levels of governance that RPPSs can adhere to, representing different degrees of complexity, ranging from Level I, the simplest, to Level IV, the most advanced. For an RPPS to obtain a certain level of governance, it has to adhere to the Pro-Management program of the Secretariat for Social Security and be approved. To achieve the highest levels of governance (III and IV) there must be a robust organizational structure with a greater number of technicians and a higher cost of maintaining the staff of the unit responsible for the investment management of the RPPS. For each of these levels, preceding governance conditions have to be implemented and proven. The higher the level of governance of a RPPS, the greater the investment limits for risky assets, as shown in Table 1.

These regulatory changes were made during a historical moment when real interest rates were falling. Currently, Brazilian federal government bonds offer real rates below the RPPS actuarial targets. Therefore, RPPSs will need to seek investments in risky assets that offer greater returns to guarantee the payment of the agreed retirement benefits. Among the assets allowed by Resolution $3,922 / 2010$, investment funds stand out: private credit fixed income (FI RF CP), hedge funds (FIM), stock funds (FIA), private equity funds (FIP), real estate (FII), overseas investment funds (FIM IE), and infrastructure (FIP-IE). These can offer higher returns than the actuarial target rates, but they are riskier.

The central hypothesis of this article is that RPPSs will not obtain satisfactory economic results capable of generating portfolios that exceed their actuarial goals, given the current low interest rate scenario, despite the recent easing of RPPS investment limits (Table 1). Therefore, the objective is to verify if the new RPPS investment limits introduced by Res. CMN 3,922/2010 enable RPPSs to build diversified investment portfolios with returns capable of reaching and exceeding their actuarial goals. Additionally, we also aim to measure the probability of these portfolios reaching the actuarial goals. Thus, it will be possible to understand the trade-off between the increased cost of implementing governance policies vis-à-vis the economic and actuarial benefit provided by the increase in investment limits in risky asset classes.

\section{THEORETICALBACKGROUND AND EMPIRICAL LITERATURE}

The assets and liabilities management in entities that manage pension plans (encompassing both public and private pension plans as well as the RPPS) is a problem of long-term intertemporal allocation choices. For this task, the deterministic models are limited, since the economic and actuarial projections needed to estimate both assets and liabilities are based on static parameters and are, of course, inadequate to deal with the uncertainty of variables such as interest rates, inflation, wage growth, price projections, mortality rates, and other economic and actuarial variables (Ribeiro \& Sagastizábal, 2015; Valladão, 2008). Also, these models do not allow the use of assets with uncertain cash flow, such as variable income assets. In addition, the regulations covering pension funds impose a number of restrictions on asset allocation that deterministic models find it hard to cope with. For this reason, more complex stochastic ALM models with greater control over the variables began to be developed in the 1990s and were essential to addressing these challenges. 


\section{Table 1 - New RPPS Investment Limits}

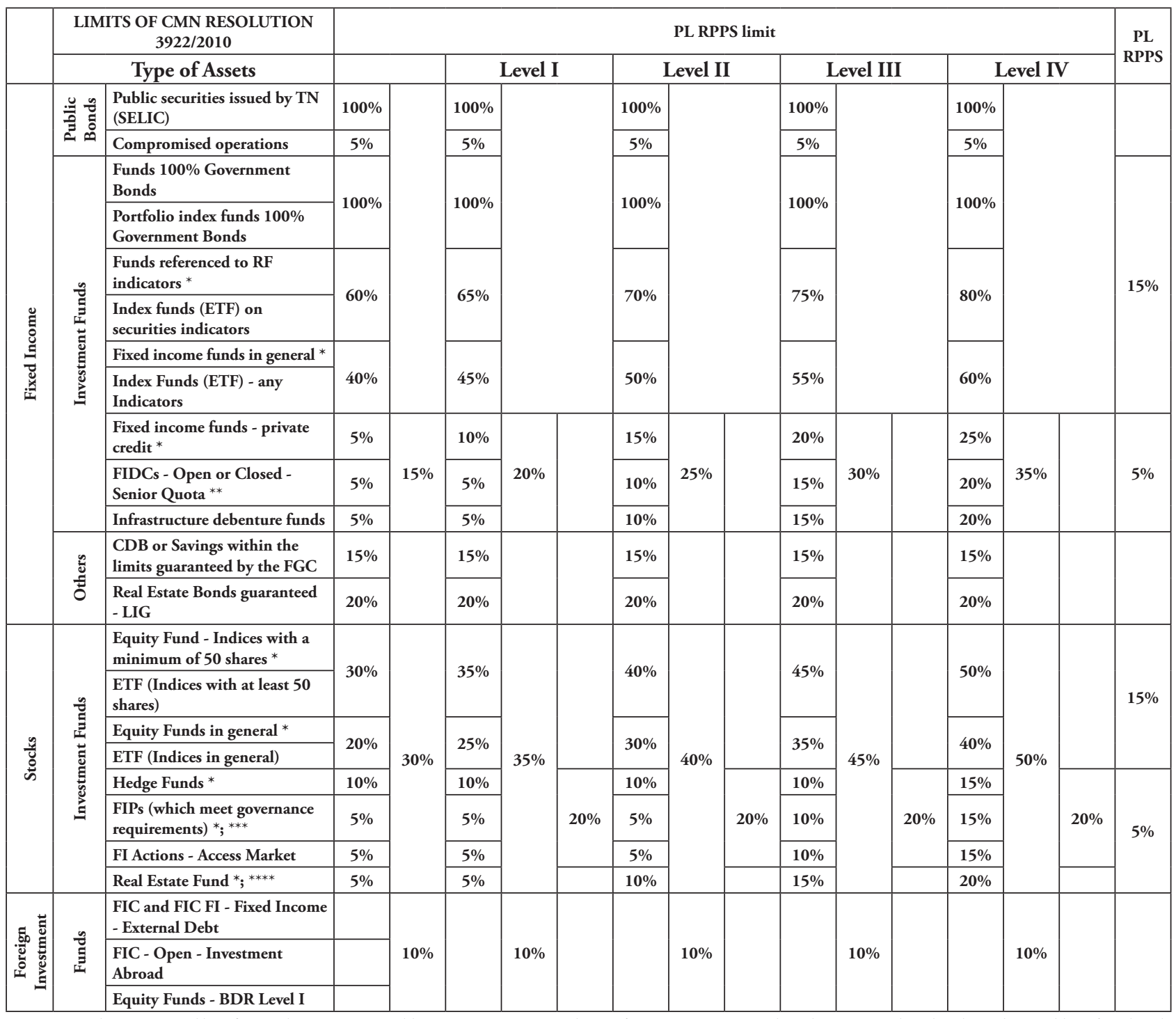

* Private credit assets issued by a financial institution or public companies or senior shares of FIDC, cannot invest abroad, ${ }^{* *}$ Manager has already made 10 public offers closed and settled, that the RPPS participate only up to $50 \%$ of the total shares, ${ }^{* * *}$ Independent company evaluation; tx performance after return of capital; manager participates with $5 \%$ and has already carried out in the last 10 years, divestment of 3 companies, ${ }^{* * *}$ Limits of $5 \%$ of the RPPS PL and $5 \%$ of the Fund's PL do not apply to quotas paid in by properties Limit valid for all funds: RPPS resources must correspond to up to $20 \%$ of the fund's PL. The total resources of an RPPS must correspond to a maximum of $5 \%$ of the total resources of the portfolio manager or administrator.. The RPPS may only invest their funds in investment funds in which, as administrator or manager, institutions authorized to operate by the Central Bank of Brazil are required to establish an audit committee and risk committee, under the terms of CMN Resolutions 3,198, 2004 , and $n^{\circ} 4557$, of 201

Source: Res. CMN 3922/2010. Social Security Secretary of the Ministry of Economy.

The development of ALM models is not recent. Leibowitz et al. (1992) conduct an important and comprehensive historical review of their evolution. The first ALM models applied to pension funds were the Dedication Models (DMs) that emerged in an economic environment with high interest rates. These models were deterministic and their main objective was to build a portfolio of fixed income securities with the lowest possible price, aiming to allocate a fixed income security with the same maturity date to each of the liability cash flows. The main advantages of these models are predictability of cash flows, reduction of reinvestment and market risks, passive (less costly) management, and, finally, more simplified asset allocation $(100 \%$ in fixed income securities). The disadvantages are the difficulty in building the portfolio (finding securities with suitable 
maturities for the liabilities), the high mathematical complexity of the models, the need to accurately project the actuarial liabilities, and the fact that the economic efficiency of the strategy is limited to scenarios with high interest rates (Ryan, 2013).

The DM model is more appropriate in situations where market interest rates are higher than the rates for actuarial targets. This is not the current scenario in Brazil. Immunization Models (IMs) gradually replaced DMs (Ryan, 2013). This new generation of IM models aimed to build fixed income securities portfolios with the highest returns possible subject to the restriction that the optimal portfolio duration ${ }^{\text {ii }}$ and convexity ${ }^{\text {iii }}$ were equal to those of the liabilities flow.

In Brazil, with the Real Plan (1994), inflation stabilized, allowing actuarial projections to be more accurate and reliable. As a result, ALM models began to be adopted more often by institutional investors. Saad and Ribeiro (2004), for example, used two models from the IM family and one DM model. The IM models in their first version used portfolio optimization models with duration restriction and later also included the convexity restriction. To mitigate the limitations of the deterministic model in dealing with the variability of future scenarios, Saad and Ribeiro (2006) presented a variant of the DM, in which the authors included two penalty factors applied to the assets: first, volatility; and second, risk aversion.

Some ALM models deal with liabilities in a deterministic way (as input parameters) and stochastic modeling applies to asset returns and the yield curve. These models use the so-called "asset only method." Models also observed in the literature treat both asset and liability variables at random, establishing stochastic models to simulate the future behavior of returns, wage growth, inflation, interest rates, and mortality rates, with the objective of estimating assets and liabilities stochastically (Dempster, Germano, Medova, \& Villaverde, 2003; Drijver \& Haneveld, 2002; Hurtado, 2008; Valladão, 2008; Ziemba, 2003).

ALM models started to combine stochastic modeling with optimization techniques under uncertainty scenarios; that is, decision-making models applied to simulated scenarios that more accurately adjust the random behavior of assets and liabilities. These optimization techniques and methods are known as stochastic linear programming (SLP). They are now applied to asset and liability management. This type of model makes it possible to include complex rules and restrictions that are necessary for incorporating real situations that investors consider, thus providing more accurate ALM models (Geyer \& Ziemba, 2008; Hosseinzadeh; \& Consigli, 2017; Lauria \& Consigli, 2017).

In order to make optimization models feasible and efficient, techniques for reducing the dimensionality of the data have been developed, such as building scenarios in multinomial trees. The latest-generation models have started to use techniques such as the decision support system (DSS) in conjunction with SLP, to deal with large numbers of variables, restrictions, and scenarios (Dutta et al., 2019; Rao et al., 2018). An interesting application of ALM models using SLP was developed by Andongwisye et al. (2018), in which a pay-as-you-go social security system was assessed for its long-term equilibrium.

Ferstl and Weissensteiner (2011) developed an ALM model using SLP to build optimal portfolios that minimize the $\mathrm{CVaR}$ (conditional value at risk) of the difference in mark-to-market value between assets and liabilities. The stochastic model used to simulate future stock returns and interest rates was the first order vector autoregression - VAR (1) - and the yield curve parameters were estimated using the Cox-Ingersoll-Ross (CIR) model. The liability flow was treated in a deterministic way, so that the stochastic treatment is restricted to the asset part.

Another study that uses $\mathrm{CVaR}$ as a quantitative risk constraint in ALM for pension funds is that of Toukourou and Dufresne (2018). They use two CVaR risk restrictions: the first was the so-called one-period integrated chance constraint (OICC); the second was the multi-period integrated chance constraint (MICC). The authors stochastically model the variables of assets (cash, bonds, real estate, and stocks) and liabilities (wage growth) using the VAR model based on the results obtained by Kouwenberg (2001) and use the flows as inputs to optimize the SLP model, with OICC and MICC measures as restrictions. Although the optimal decisions (portfolios) of the OICC and the MICC are not the same, the total costs are very close, showing that the MICC can be a good alternative because it is less volatile.

In Brazil, the SLP technique has also been applied to stochastic ALM models to evaluate pension funds in the country. De Oliveira et al. (2017) used stochastic differential equations (SDE) with geometric Brownian motion (GBM) to generate stock price scenarios and the mean-reverse CIR model to simulate the interest curve structure. In that work, both the Brazilian regulatory rules regarding investment limits per asset, as well as the minimum 
solvency ratio requirement (which determines that this ratio cannot be less than one for two consecutive years), were incorporated through the inclusion of constraints in the optimization model. The results suggest that, for lower interest rate scenarios (below 6\% p.a.), the optimal portfolios suggested by the ALM model recommend greater allocation into equity assets (greater than 40\%).

To achieve our objectives, we will use the meanCVaR optimization model, as implemented by Ferstl and Weissensteiner (2011), to obtain the optimal portfolios that will emulate future scenarios, thus testing the hypothesis that these portfolios are sufficiently profitable to reach or exceed actuarial targets. The optimization model will be implemented with two types of restrictions: (i) regulatory, which will cover investment limits by asset class given a level of governance; and (ii) risk measures, which is the CVaR of the asset portfolio for a given level of confidence $\alpha$. In addition, price scenarios will be generated for the assets that will make it possible to simulate the evolution of the optimal portfolios to measure the probability of the portfolios reaching the actuarial goals over time. For the asset price simulation, stochastic differential equations (GBM) will be used.

\section{METHODOLOGY}

We obtained information from four RPPSs that were willing to anonymously provide their actuarial liabilities flows, pension income flows, and their actuarial goals. With this information and the value of the investment portfolios, we were able to verify whether the RPPSs are in actuarial equilibrium, that is, whether their assets are sufficient to honor the payment commitments for present and future benefits. Let $A_{t}^{k}$ and $L_{t}^{k}$, respectively, be the flows resulting from the mark-to-market $\left(M t M^{\text {iv }}\right)$ of the assets and liabilities of the $\mathrm{k}$-th RPPS, where $\mathrm{k}=1,2,3,4$, measured at time $t$, and the actuarial equilibrium is calculated by the solvency ratio defined by $S_{t}^{k}=A_{t}^{k} \cdot\left(L_{t}^{k}\right)^{-1}$. For $S_{t}^{k}$ to make economic sense, it is necessary for the same pricing methods to focus on $A_{t}^{k}$ and $L_{t}^{k}$. Therefore, both $A_{t}^{k}$ and $L_{t}^{k}$ were measured via $M t M$.

It is noteworthy that the RPPS recognizes the amount of the discounted liability at a fixed interest rate and it is equal to its actuarial target rate. As an immediate implication, this treatment will underestimate the value of the liability whenever the rates of the actuarial goals are higher than the market interest rates, which are fundamental for measuring $M t M$.

Regarding $S_{t}^{k}$, when $A_{t}^{k}=L_{t}^{k}$, then the entity is in actuarial equilibrium. If $A_{t}^{k}>L_{t}^{k}$, there is an actuarial surplus, and if $A_{t}^{k}<L_{t}^{k}$, there is an actuarial deficit. Using the actuarial liability flows, it is possible to measure the duration of each RPPS, which will be called $D_{k}$.

In cases where there is an actuarial deficit $\left(A_{t}^{k}<L_{t}^{k}\right)$, $S_{t}^{k}$ can be interpreted as the percentage necessary for $A_{t}^{k}$ to be equal to $L_{t}^{k}$. That is, it is the additional rate of return $\left({ }^{i k}\right)$ that is necessary for $A_{t}^{k}$ (assets) to be sufficient to satisfy the actuarial equilibrium. Algebraically, as $S_{t}^{k} \cdot A_{t}^{k}=L_{t}^{k}$, and where $S_{t}^{k}=i_{t}^{k}$, we have $i_{t}^{k} \cdot A_{t}^{k}=L$, where $i_{t}^{k}$ is the additional rate of return needed to achieve $S_{t}^{k}=1$. Since $i_{t}^{k}$ is an effective rate, one needs to convert it into an annual rate as follows: $y i_{t}^{k}=\left(\left(1+i_{t}^{k}\right)^{1 / D}-1\right)$. Thus, $y^{i_{t}^{k}}$ will be interpreted as the additional annual rate of return which, compounded in D years, is equivalent to the effective rate $i_{t}^{k}$. Therefore, the required rate of return, denominated as $r_{t, k}^{\text {optimal portfolio }}$, to be used to choose the optimal portfolio of said RPPS at time t, is:

$$
r_{t, k}^{\text {optimal portfolio }}=\left\{\begin{array}{l}
\left(1+{ }_{y} i_{t}^{k}\right) \times\left(1+M A_{t}^{k}\right)-1, \text { if } A_{t}^{k}<L_{t}^{k} \\
M A_{t}^{k} \quad, \text { if } A_{t}^{k} \geq L_{t}^{k}
\end{array}\right.
$$

where $M A_{t}^{k}$ is the (annual) actuarial goal rate of the k-th RPPS at time t.

The mathematical ALM model chosen for building optimal portfolios was the mean-CVaR model, as defined in Equation (6), considering the return required for the optimal portfolio equal to that established by Equation (1). The objective of this work is to verify if there is a viable solution for obtaining the optimal portfolio, that is: if it is possible to build a portfolio capable of getting a return equal to or greater than $r_{t, k}^{\text {optimal portfolio }}$, subject to the investment restrictions imposed on RPPSs by Res. CMN 3,922/2010 and its amendments. If the optimal portfolios found meet the investment restrictions capable of providing the $r_{t, k}^{\text {optimal portfolio }}$ return necessary for the actuarial equilibrium, then simulations of the evolution of the portfolio will be carried out over time, using generation future asset price scenarios.

With the future simulations of $A_{t}^{k}$, we can obtain estimates of the optimal portfolios' profitability and also can measure the probabilities of these portfolios reaching the expected return. Another evaluation will be a comparative analysis of the results considering the normative requirements and an unrestricted investment space. In this way, the impacts of investment restrictions can be assessed. 


\section{I. RISK MEASURES}

An important and widely used risk measure in finance is expected shortfall $(E S)$, which is also known as $\mathrm{CVaR}$ (conditional value at risk). This measure is calculated as the weighted average of the extreme losses, at the tail of the $f$ distribution of the returns of a portfolio with weight vector $w$, in addition to the quantile $(\alpha)$ established by VaR. The CVaR is defined (Krokhmal, Uryasev, \& Palmquist, 2001) by:

$\operatorname{CVaR}_{\alpha}(w, \zeta)=\zeta+(1-\alpha)^{-1} \int_{\xi \in \mathbb{R}}[f(w, \xi)-\zeta]^{+} p(\xi) d \xi$

Equation (2) has an intrinsic relationship with VaR, since:

$\operatorname{CVaR}_{\alpha}(w, \zeta)=\mathbb{E}\left[\xi \mid \xi \geq \zeta_{\alpha}(\xi)\right]=\mathbb{E}[\xi \mid \xi \geq \operatorname{VaR}]$,

where

$\left\{\begin{aligned} \zeta_{\alpha}(\xi) & =\operatorname{VaR}=\inf \{\zeta \mid \mathbb{P}(\xi \leq-\zeta) \geq \alpha\} \\ \operatorname{VaR} & =-z_{\alpha} \sqrt{w^{T} \Sigma w}\end{aligned}\right.$

with the weight vector $w$ of the portfolio allocation, $\Sigma$ represents the matrix of linear correlations between the assets, and $z_{\alpha}$ is the quantile of order $\alpha$ to the left of a normal $(0,1)$ distribution.

It is important to highlight that the VaR calculated using the parametric method assumes that the assets' returns follow a normal distribution and are second-order stationary. However, when estimated by market data, returns can often show asymmetry and a high kurtosis, especially in more volatile markets. In addition, $\mathrm{VaR}$ is a quantile and does not capture the worst cases. The immediate implication is that risk estimates $(\mathrm{VaR})$ are underestimated. This is the basic reason why $\mathrm{CVaR}$ is a more adequate measure than $\mathrm{VaR}$.

Similar to in the work of Rockafellar and Uryasev (2000), CVaR can be approximated using scenarios, as according to Equation (1):

$$
\begin{aligned}
& \operatorname{CVaR}_{\alpha}(w, \zeta)=\zeta+(1-\alpha)^{-1} \int_{\xi \in \mathbb{R}}[f(w, \xi)-\zeta]^{+} p(\xi) d \xi \\
& \approx \zeta+(1-\alpha)^{-1} \sum_{s=1}^{S}\left[f\left(w, \xi_{S}\right)-\zeta\right]^{+} p_{s}
\end{aligned}
$$

where $f\left(w, \xi_{s}\right)$ is the portfolio loss function and $\left[f\left(w, \xi_{s}\right)-\zeta\right]^{+}$denotes the event of excess in relation to the global quantile $\zeta$.
The term $\left[f\left(w, \xi_{s}\right)-\zeta\right]^{+} p_{s}$ from Equation (4) can be reduced to:

$$
\begin{aligned}
& {\left[f\left(w, \xi_{s}\right)-\zeta\right]^{+}=z_{S}} \\
& z_{S} \geq f\left(w, \xi_{s}\right)-\zeta \\
& z_{s} \geq 0
\end{aligned}
$$

\subsection{THE OPTIMIZATION PROBLEM}

In this work, the optimization problem to be implemented is analogous to that of Cho (2008). The mathematical definition of this mean-CVaR optimization model is established by:

minimize $\left\{\zeta+(1-\alpha)^{-1} \sum_{s=1}^{S} z_{s} p_{s}\right.$

Subject to $\sum_{i=1}^{n} w_{i}=1$

$\sum_{i=0}^{n} w_{i} \mathbb{E}\left[\xi_{i}\right] \geq R$

$z_{S} \geq f\left(w, \xi_{S}\right)-\zeta$

$z_{s} \geq 0$

where $\mathrm{R}$ is the actuarial goal for each RPPS. Further discussions about this optimization model are found in Krokhmal et al. (2001).

\subsection{THE PORTFOLIOS' SET OF RESTRICTIONS}

The optimization problem defined by the set of Equations (5) has two restrictions sets. The first set of restrictions is defined by the investment legislation in force for the RPPS, which, depending on the level of governance, establishes minimum and maximum allocation limits for each type of assets. Thus, asset allocation limits would have restrictions defined by:

$w_{G, n}^{\min } \leq w_{G, n} \leq w_{G, n}^{\max }$,

with $G=1,2,3$ and 4 - representing the levels of governance of the RPPS - and $n=1,2, \ldots, N$, denoting the amount of assets offered for investment. 
On the other hand, the second set refers to the restrictions of the risk measure defined by a confidence level $\alpha$ applied to CVaR. As a premise, $\alpha$ will be $95 \%$, that is, the optimal portfolios to be selected will be the most efficient, with a risk measure of $\mathrm{CVaR}_{95 \%}$.

\subsection{GENERATION OF SCENARIOS}

The scenarios to be generated for each time $t$ will be composed of the price series for each $N$ assets simulated in a correlated way. For the generation of asset prices, we use the stochastic differential equations models as presented in Oliveira (2018). Thus, the GBM model will be adopted to simulate the price of variable income assets. The covariance structure of the assets will be estimated by the sample covariance matrix $\hat{\Sigma}$ of the historical assets' series of returns. The assets' prices modeled with SDE will be described by:

$d \xi_{i t}=\mu\left(\xi_{i t}, t\right) d t+\sigma\left(\xi_{i t}, t\right) d W_{i t}$,

where $W_{i t}$ is a Wiener process, $\mathrm{N}(0, \Delta)$, in which $t<t+\Delta$. To generate the correlated asset prices, it is necessary to use the residuals' covariance structure of the assets' returns, as presented in Dempster et al. (2003). The correlation between two assets $i$ and $j$ is defined by:

$d W_{i} \cdot d W_{j}=\rho_{i j} d t$,

where $\rho_{i i}=1$ for any $i$. Without loss of generality, variableincome assets $\xi_{1 t}$ and fixed-income assets $\xi_{2 t}$ will be presented. Using the GBM model to simulate the prices of variable-income assets $\xi_{1}$, we have the following:

$d \xi_{1 t}=\mu \xi_{1 t} d t+\sigma \xi_{1 t} d W_{1 t}$

and, knowing that the GBM model offers a closed form solution to estimate the price $\xi_{1 t}$ (NEFTCI, 2013) when the underlying distribution is a log-normal of mean $\mu$ and variance $\sigma^{2}$, the exact value of $\xi_{1 t}$ is:

$\xi_{1 t}=\xi_{1(t-1)} e^{\left(\mu-\frac{1}{2} \sigma^{2}\right) d t+\sigma \varepsilon \sqrt{d t}}$,

where $\varepsilon \sim N(0,1)$.

\section{ANALYSIS OF RESULTS}

\section{I. DATABASE}

To fit the ALM models, two main groups of data are needed: (a) the market data of the asset returns and (b) the data on the RPPS actuarial liabilities. The asset returns data were obtained from several data sources such as $[\mathrm{B}]^{3}$, ANBIMA, IBGE, BACEN, Bloomberg, and CETIP. The RPPS data (both the investment positions of the mathematical provisions' guarantee assets related to the granting of benefits, as well as the future cashflows of the actuarial liabilities) were obtained directly from the managers. Contacts within four RPPSs provided the data to execute this work, as long as their names were kept anonymous.

Using the long-term real interest curves to calculate the additional rates of return $\left(i_{t}^{k}\right)$, it is observed that the annual discount rates that are in force in Brazil today ( $3.7 \%$ p.a.), when the assets and liabilities are markto-market, accentuate the actuarial gap of the RPPSs. Table 2 shows the $i_{t}^{k}$ and $r_{t, k}^{\text {optimal portfolio }}$ rates calculated for each of the RPPS that provided the information.

It is possible to note that, for three out of the four RPPSs, the discount rates for assets and liabilities are different, revealing the need to obtain higher rates of returns on the portfolios to offset the actuarial deficit effect $\left(A_{t}^{k}<L_{t}^{k}\right)$. Thus, the subsequent comparative analysis will be based on the actuarial targets of $6 \%$ p.a., since all RPPSs present this order of magnitude for the difference between $i_{t}^{k}$ and $r_{t, k}^{\text {optimal portfolio }}$, so that the conclusions and results are sufficiently generalized.

Table 3 presents the summary of the market assets used to represent the investment classes permitted by the RPPS legislation. The last five years of price

Table 2 - Additional annual return rates $y^{i_{t}^{k}}$ and target return $r_{t, k}^{\text {optimal portfolio }}$

\begin{tabular}{ccc}
\hline RPPS & $\begin{array}{c}\text { Additional annual } \\
\text { return rate } \boldsymbol{i}_{\boldsymbol{t}}^{\boldsymbol{k}}\end{array}$ & $\begin{array}{c}\text { Target return } \\
\boldsymbol{r}_{\boldsymbol{t}, \boldsymbol{k}} \text { optimal portfolio }\end{array}$ \\
\hline 1 & $0.00 \%$ & $6.00 \%$ \\
2 & $5.34 \%$ & $11.66 \%$ \\
3 & $1.61 \%$ & $7.71 \%$ \\
4 & $1.30 \%$ & $7.38 \%$ \\
\hline
\end{tabular}

Source: own elaboration, based on information provided by the managers of the RPPS. 
Table 3 - Descriptive statistics for assets associated with investment classes

\begin{tabular}{|c|c|c|c|c|c|c|c|c|}
\hline \multirow[b]{2}{*}{ Assets } & \multirow[b]{2}{*}{ Assets Class } & \multicolumn{5}{|c|}{ Annual Return } & \multirow{2}{*}{$\begin{array}{c}\text { Annual } \\
\text { Rate for the } \\
\text { Period }\end{array}$} & \multirow[b]{2}{*}{$\begin{array}{l}\text { Spread Over } \\
\text { CDI }\end{array}$} \\
\hline & & Mean & Med. & Min. & Max. & $\begin{array}{c}\text { Standard } \\
\text { Deviation }\end{array}$ & & \\
\hline IMAB & $\begin{array}{c}\text { Federal } \\
\text { Government } \\
\text { Bonds }\end{array}$ & $12.82 \%$ & $13.67 \%$ & $-14.29 \%$ & $27.34 \%$ & $8.86 \%$ & $16.29 \%$ & $1.50 \%$ \\
\hline IDA_DI & $\begin{array}{l}\text { DI-indexed } \\
\text { Credit }\end{array}$ & $10.61 \%$ & $10.74 \%$ & $5.41 \%$ & $15.59 \%$ & $2.62 \%$ & $10.81 \%$ & $0.75 \%$ \\
\hline IDA_IPCA & $\begin{array}{l}\text { IPC-indexed } \\
\text { Credit }\end{array}$ & $12.09 \%$ & $12.44 \%$ & $-3.08 \%$ & $19.91 \%$ & $4.77 \%$ & $13.12 \%$ & $1.57 \%$ \\
\hline IBOVESPA & $\begin{array}{c}\text { Stock } \\
\text { Exchange }\end{array}$ & $6.29 \%$ & $6.72 \%$ & $-30.82 \%$ & $56.30 \%$ & $16.83 \%$ & $19.57 \%$ & $6.00 \%$ \\
\hline IFM_I & $\begin{array}{l}\text { Institutional } \\
\text { Multimarket } \\
\text { Funds }\end{array}$ & $9.50 \%$ & $9.75 \%$ & $5.57 \%$ & $32.05 \%$ & $2.32 \%$ & $10.01 \%$ & $1.15 \%$ \\
\hline IFIX & $\begin{array}{l}\text { Real Estate } \\
\text { Funds }\end{array}$ & $11.25 \%$ & $11.57 \%$ & $-27.01 \%$ & $40.24 \%$ & $13.79 \%$ & $19.09 \%$ & $4.00 \%$ \\
\hline IBX (PE) & $\begin{array}{c}\text { Private } \\
\text { Equity Funds }\end{array}$ & $9.18 \%$ & $8.75 \%$ & $-28.55 \%$ & $53.97 \%$ & $14.45 \%$ & $19.92 \%$ & $11.00 \%$ \\
\hline MSCI_W & $\begin{array}{c}\text { Investment } \\
\text { Abroad }\end{array}$ & $18.29 \%$ & $19.57 \%$ & $-22.62 \%$ & $51.18 \%$ & $13.99 \%$ & $15.79 \%$ & $5.28 \%$ \\
\hline
\end{tabular}

Source: own elaboration, based on Bloomberg's historical records.

Table 4 - Correlation matrix between the assets considered in the analysis

\begin{tabular}{lrrrrrrcc}
\hline & IMAB & IDA_DI & IDA_IPCA & IBOV & \multicolumn{1}{c}{ IFM_I } & IFIX & IBX (PE) & MSCI_W \\
\hline IMAB & $100.00 \%$ & $21.51 \%$ & $93.63 \%$ & $51.19 \%$ & $41.74 \%$ & $85.85 \%$ & $47.83 \%$ & $-51.45 \%$ \\
IDA_DI & $21.51 \%$ & $100.00 \%$ & $28.70 \%$ & $4.73 \%$ & $91.96 \%$ & $31.08 \%$ & $-5.21 \%$ & $-28.44 \%$ \\
IDA_IPCA & $93.63 \%$ & $28.70 \%$ & $100.00 \%$ & $29.11 \%$ & $47.51 \%$ & $84.86 \%$ & $27.42 \%$ & $-38.92 \%$ \\
IBOV & $51.19 \%$ & $4.73 \%$ & $29.11 \%$ & $100.00 \%$ & $9.01 \%$ & $50.61 \%$ & $97.20 \%$ & $-63.70 \%$ \\
IFM_I & $41.74 \%$ & $91.96 \%$ & $47.51 \%$ & $9.01 \%$ & $100.00 \%$ & $46.38 \%$ & $-1.13 \%$ & $-23.33 \%$ \\
IFIX & $85.85 \%$ & $31.08 \%$ & $84.86 \%$ & $50.61 \%$ & $46.38 \%$ & $100.00 \%$ & $52.72 \%$ & $-45.73 \%$ \\
IBX (PE) & $47.83 \%$ & $-5.21 \%$ & $27.42 \%$ & $97.20 \%$ & $-1.13 \%$ & $52.72 \%$ & $100.00 \%$ & $-61.81 \%$ \\
MSCI_W & $-51.45 \%$ & $-28.44 \%$ & $-38.92 \%$ & $-63.70 \%$ & $-23.33 \%$ & $-45.73 \%$ & $-61.81 \%$ & $100.00 \%$ \\
\hline
\end{tabular}

Source: own elaboration, based on Bloomberg's historical records.

quotations and interest rates, counted retrospectively as of $12 / 31 / 2019$, have been used as a history. These data were used to calculate annual returns and estimate the dependency structure between market assets.

Table 3 shows that the class of variable income assets - assets that can be allocated on the stock exchange (IBOVESPA), in real estate funds (IFIX), in private equity funds (IBX_PE), and in stock exchanges abroad (MSCI_W) - have higher average returns and dispersion than the fixed income asset class, represented by federal government bonds (IMAB), credit (IDA_DI and IDA_IPCA), and institutional multimarket funds (IFM_I). This behavior was expected according to the classical theory of finance, which argues that there is a positive relationship between risk and return.
Table 4 shows that MSCI_W is the asset class with the highest negative correlation with the others. That is, it is the asset that diversifies risk the most.

As in the Brazilian market there is no benchmark to represent the private equity $(\mathrm{PE})$ investment class, the results presented by Minardi, Bortoluzzo, and Moreira (2017) were used to estimate the mean and the volatility of the returns on this asset class. In their work, descriptive statistics were estimated on the performance and duration of investments made by PE funds in Brazil from 1994 to 2014. The study adopted the multiple on invested capital (MOIC) as a measure of performance, calculated in BRL and deflated by the IPCA, and, for the measurement of investment duration, they used the holding period in 
years (difference in years between the entry and exit of investments).

With these statistics for the MOIC and the PE investment holding period, the internal rate of return (IRR) statistics were calculated, using an approximation used by Minardi and Moreira (2014), as according to Equation (10). The average and standard deviation of the IRR of these investments were, respectively, $21.36 \%$ and $33.01 \%$.

$$
I R R=\left[(\text { MOIC })\left(\frac{1}{\text { Holding Period }}\right)-1\right] .
$$

We chose to use the IBX historical series (Brazil Index), a variable-income index, as a proxy for PE assets, but with volatility adjustments to the values as estimated by Minardi, Bortoluzzo, and Moreira (2017).

\subsection{EFFICIENT PORTFOLIOS}

To model the efficient frontiers, as well as to implement the optimization problem, the $\mathrm{R}$ software version 3.6.1 was used. To obtain the efficient portfolios, the initial parameters were: (i) the investment limits shown in Table 1, which defined the restrictions and allocation limits for the RPPS; and (ii) governance levels I, II, III, and IV. According to the legal provisions, the higher the level of governance of the RPPS is, the greater the limits are for investment in risk asset classes.

Additionally, for the sake of comparison, a "free model" was considered, in which it would be possible to allocate resources freely in all investment classes without restrictions. As mentioned in sections 3.2 and 3.3, the optimization model implemented was the mean-CVaR efficient model, according to the optimization problem given by the set of equations 5. Figure 1 shows the efficient frontiers obtained as a result of the six optimization models.

The y-axis in Figure 1 is presented in the form of a real interest rate, in order to facilitate comparison with the actuarial targets of the RPPS, which are also real interest. It is important to note that full allocation in some of the assets is inadmissible for restricted models, due to legal restrictions, and all the presented frontiers already consider the limits stipulated for each level of governance.

For each point on the efficient frontiers an optimal portfolio is established, from which the percentage of allocation in each of the risk assets can be extracted. Figure 2 shows these efficient portfolio allocations for each of the frontiers obtained by the optimization models shown in Figure 1. Through Figure 2, it is possible to see that the restricted model (with the lowest risk limit) forces

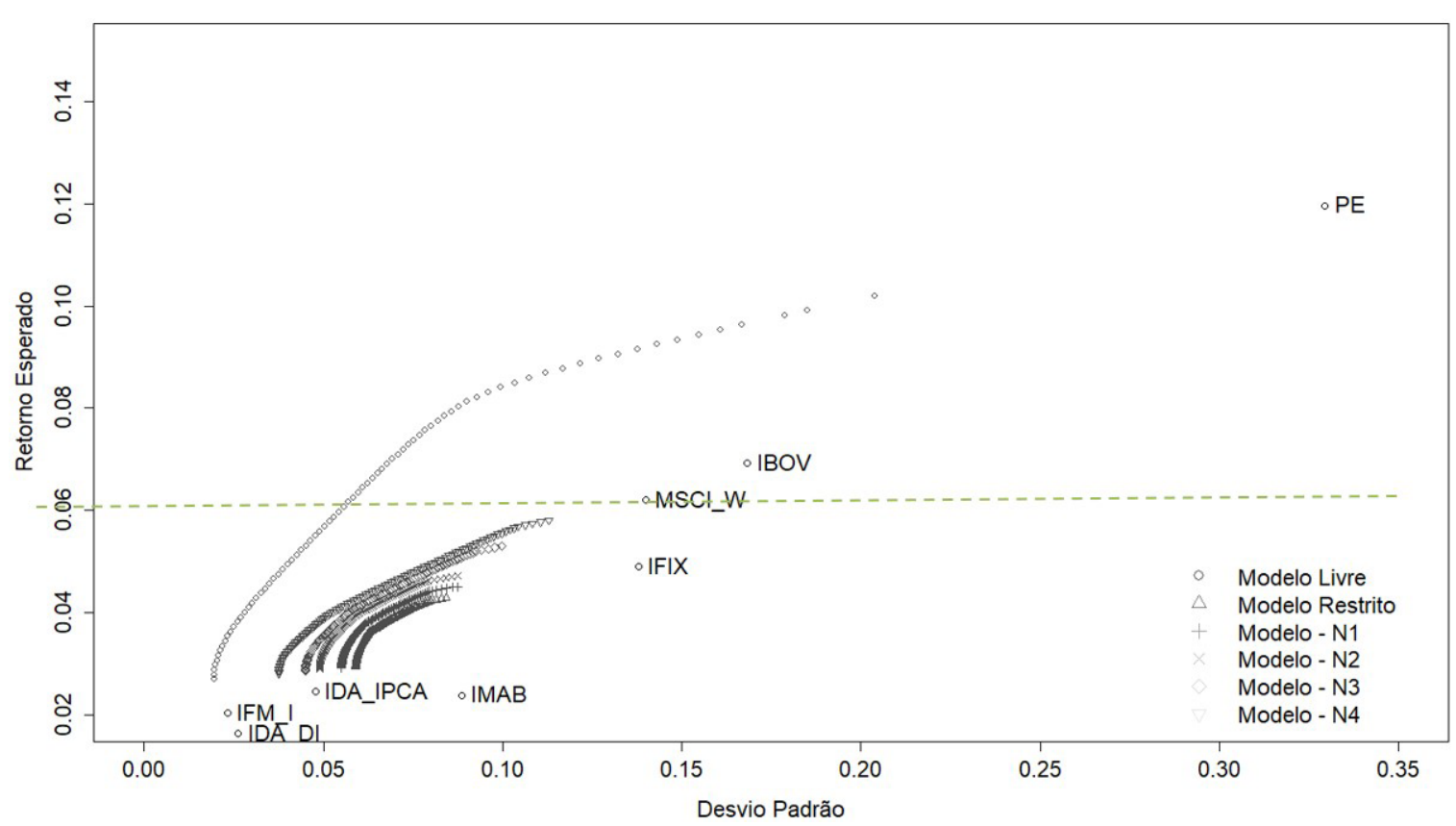

Figure 1 - Efficient frontiers for the real interest rates of the free model, standard model, and four levels of governance instituted by Res. CMN 3,922/2010, considering $\operatorname{CVaR}_{\ddot{\mathrm{u}}}$.

Source: own elaboration. 

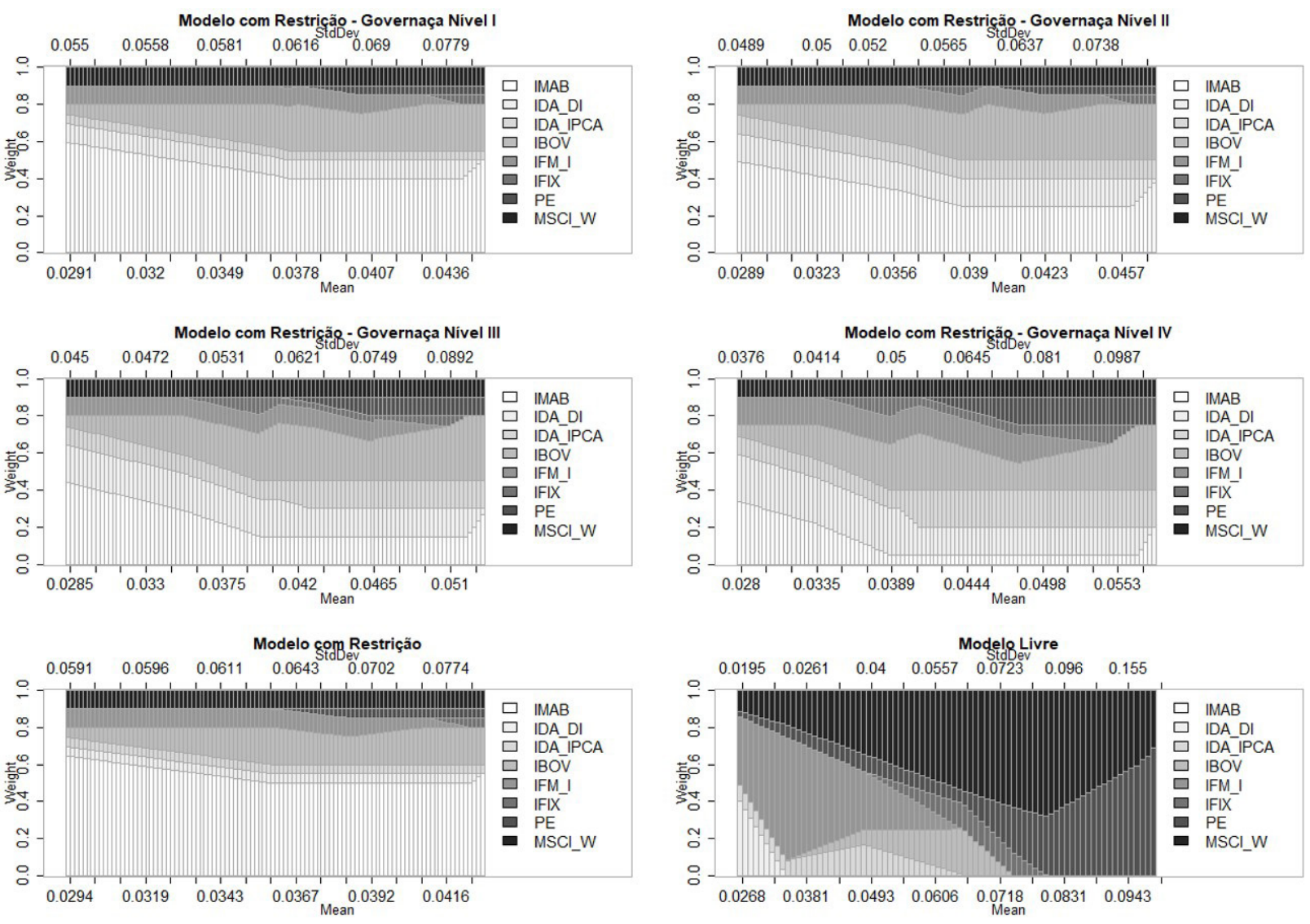

Figure 2 - Composition of efficient portfolios, for each of the six models

Source: own elaboration.

the RPPSs to allocate from $70 \%$ to $80 \%$ of their funds in federal government bonds, meaning the expected return falls far below the rate of the current actuarial goals (less than $6 \%$ p.a.).

Figure 3, which shows the expected return and risk of each of the 90,000 simulations of random portfolios for each model, provides evidence that the current investment rules (Res. CMN 3,922/2010) restrict RPPSs so much that they fail to achieve the return necessary to meet their actuarial goals. This conclusion is particularly stronger for those classified in lower levels of governance. Among the simulated portfolios, only $0.21 \%$ of the level IV restricted model portfolios were able to achieve the expected return of $6 \%$ p.a. and, in the case of the level III restricted model, no single portfolio was able to achieve the goal. Moreover, even models with higher risk limits (higher levels of governance, i.e. levels III and IV) can only obtain portfolios with returns close to the actuarial target (6\% p.a. in real interest) if they assume portfolio allocations with the highest-level possible risk. The other models are unable to offer allocations capable of exceeding the profitability of the actuarial goal.

Analyzing the risk values of the efficient portfolios in Table 5, one thing is notable: the risk offered by the free model portfolio is less than half the risk of the level III and IV portfolios, showing that investment restrictions bring risk to governance models that is at least twice that of the free model.

\subsection{VIABILITY}

The viability of portfolios is associated with the possibility of those portfolios achieving real interest rates above $6 \%$ p.a. According to the results presented by Figures 1 and 3, we verify that only the free model offers a diversity of portfolios that easily achieve the actuarial goal. Models III and IV can only achieve the return objective at the maximum risk limit of their frontiers.

Another interesting finding when analyzing the data in Table 5, which provides information on the portfolios' composition and the risk and return measures 


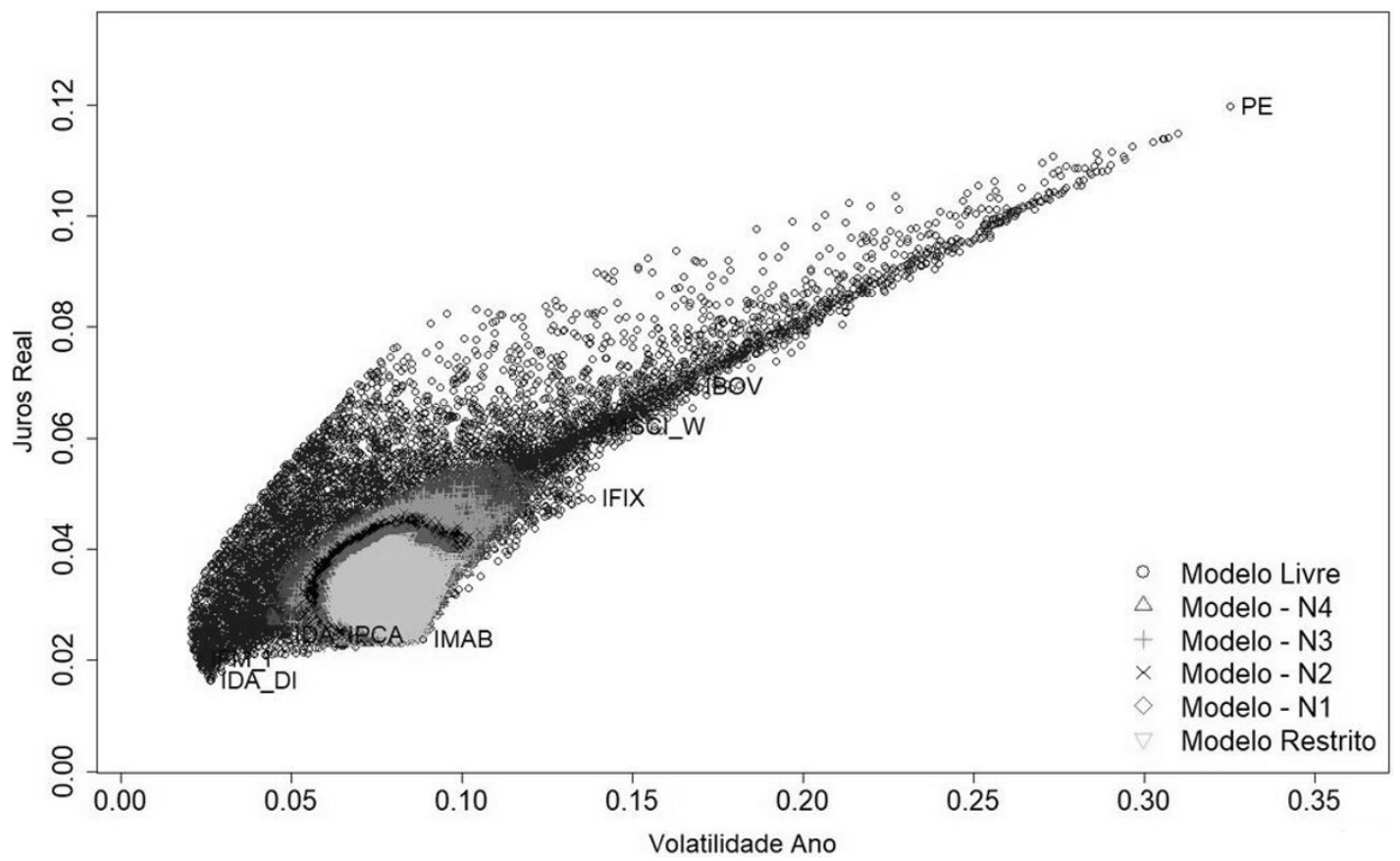

Figure 3 - Simulation of 90,000 random portfolios for levels I, II, III, and IV and the free and restricted models

Source: own elaboration.

Table 5 - Statistics of the portfolios of the restricted models for governance levels III and IV and the free model that reached the actuarial target of $6 \%$ p.a. in real returns.

\begin{tabular}{lccc}
\hline & \multicolumn{3}{c}{ Portfolio } \\
\cline { 2 - 4 } & $\begin{array}{c}\text { Level III } \\
\text { Model }\end{array}$ & $\begin{array}{c}\text { Level IV } \\
\text { Model }\end{array}$ & Free Model \\
\hline Mean & $5,32 \%$ & $5,80 \%$ & $6,06 \%$ \\
Standard Deviation & $10,15 \%$ & $11,22 \%$ & $5,56 \%$ \\
IMAB & $30 \%$ & $20 \%$ & $0 \%$ \\
IDA_DI & $0 \%$ & $0 \%$ & $0 \%$ \\
IDA_IPCA & $15 \%$ & $20 \%$ & $6 \%$ \\
IBOV & $35 \%$ & $35 \%$ & $15 \%$ \\
IFM_I & $0 \%$ & $0 \%$ & $12 \%$ \\
IFIX & $0 \%$ & $0 \%$ & $9 \%$ \\
PE & $10 \%$ & $15 \%$ & $10 \%$ \\
MSCI_W & $10 \%$ & $10 \%$ & $48 \%$ \\
\hline
\end{tabular}

Source: own elaboration.

for each portfolio, is that the free model achieves a real return of $6 \%$ p.a. with almost half of the volatility (risk) of the level III and IV models. In other words, portfolios from the models with regulatory restriction levels III and IV need to be exposed to twice the risk of the free model to offer the same expected return. Obviously, the free model is a hypothetical and theoretical model, in addition to having greater illiquidity as a result of allocating 50\% to real estate assets and FIP. But the comparative exercise provides evidence that relaxing investment limits for RPPS allocations, in addition to enabling the achievement of return targets, would also offer RPPSs the possibility of building portfolios with less risk exposure.

Observing the allocation suggested by the free model, attention is drawn to the $48 \%$ allocation in the "investments abroad" asset class. This class is the one that most diversifies the portfolio and, consequently, reduces its risk. This is a result of the negative correlations of the return on these assets shown in Table 4. Two other points are important. The first is that the current legislation allows $10 \%$ to be invested in this asset class (which is little, given the results). The second is that the allocation into this asset class by Brazilian RPPSs, according to a report by the Secretariat of Social Security, is currently less than $1 \%$.

Generally, investments abroad are made in foreign currency and, when there are situations of crisis or great uncertainty in the Brazilian economy (such as an increase in basic interest rates, inflation, events related to politics, among others), the USD rate tends to rise. Thus, whoever has investments indexed to the exchange rate is able to obtain returns that offset the losses in other traditional investments, thus diversifying their portfolio. 


\subsection{BEHAVIOR AND HISTORICAL EVOLUTION}

This section presents the behavior over time of the profitability of the optimal portfolios of the free model and restricted models III and IV. As presented in section 3.4, the models of stochastic differential equations were used to simulate risk asset price scenarios. These models for generating returns and prices were also implemented in the $\mathrm{R}$ software, as well as the portfolio reallocation algorithm. Portfolio reallocations are scheduled to occur annually, which emulates the entities' investment decisions, as RPPSs annually review their investment policies. With these datasets, and the percentage allocations of the optimal portfolios, the portfolio results were projected, considering the portfolio's annual reallocation.

Figure 4 shows the historical behavior of the simulation of 1,000 future scenarios for these portfolios. It is possible to see that the portfolios carry an enormous risk of generating low returns and even negative returns in the short term. Through Table 6, it is noted that the probability that the optimal portfolio of restricted model III will obtain negative returns at the end of the 12, 36, and 120 months is $34.2 \%, 21.4 \%$, and $6.4 \%$, respectively.
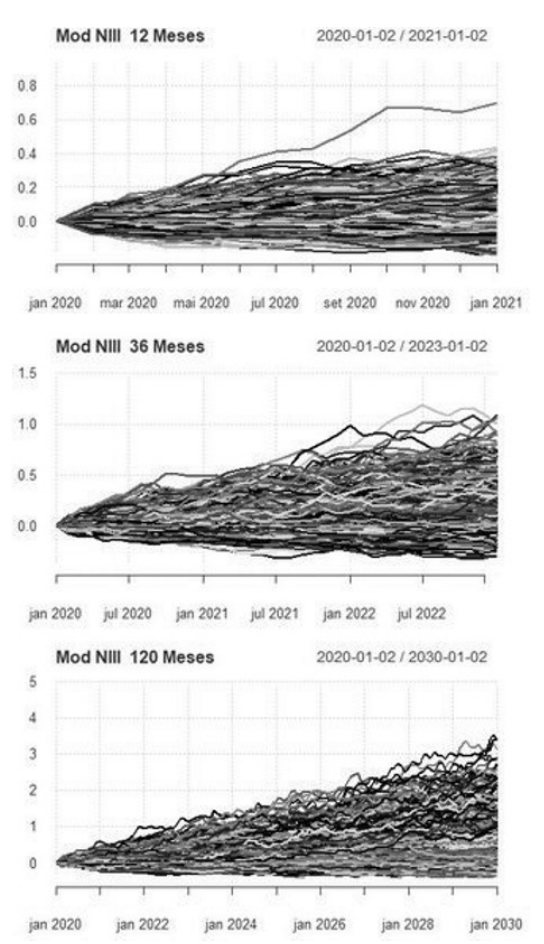
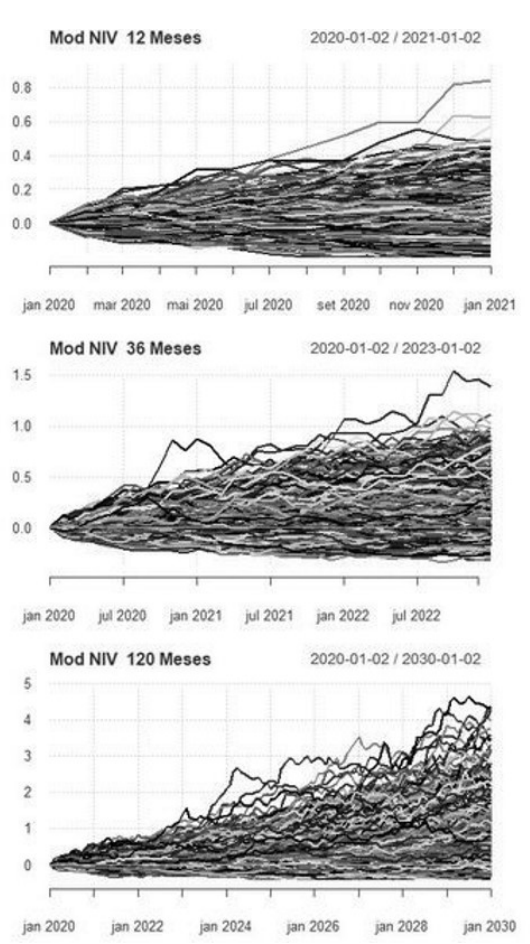
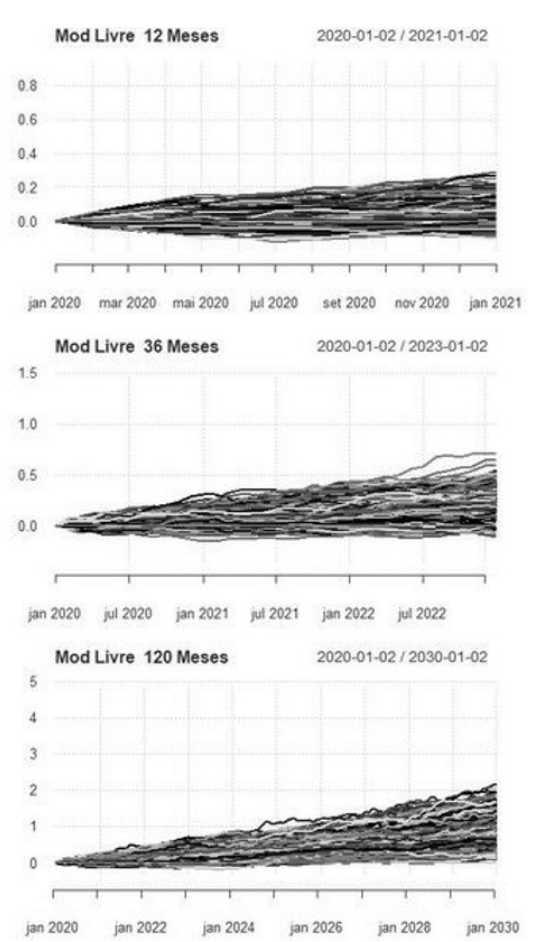

Figure 4 - Simulation of the future temporal evolution of the optimal portfolios of the free model and the level III and IV models that achieved real profitability of 6\% p.a, in horizons of 1, 3, and 10 years. Source: own elaboration.

Table 6 - Estimated probabilities of the future performance of the optimal portfolio of the free model and the level III and IV restricted models that achieved 6\% p.a. in real interest.

\begin{tabular}{|c|c|c|c|c|c|c|}
\hline \multirow{3}{*}{$\begin{array}{c}\text { Period } \\
\text { (months) }\end{array}$} & \multicolumn{6}{|c|}{ Probability } \\
\hline & \multicolumn{3}{|c|}{ Real return portfolio profitability to be negative at the end } & \multicolumn{3}{|c|}{ Portfolio profitability exceeds $6 \%$ p.a. (real interest) } \\
\hline & Level III Model & Level IV Model & Free Model & Level III Model & Level IV Model & Free Model \\
\hline 12 & 0.342 & 0.359 & 0.153 & 0.463 & 0.450 & 0.516 \\
\hline 36 & 0.214 & 0.233 & 0.038 & 0.418 & 0.445 & 0.485 \\
\hline 120 & 0.064 & 0.068 & 0.000 & 0.381 & 0.429 & 0.515 \\
\hline
\end{tabular}

Source: own elaboration. 
Table 7 - Summary results of the $\mathbf{1 , 0 0 0}$ simulations of future performance of the free model and level III and IV models that reached $6 \%$ p.a. in real interest.

\begin{tabular}{|c|c|c|c|c|c|c|c|c|}
\hline \multirow{2}{*}{$\begin{array}{c}\text { Period } \\
\text { (Months) }\end{array}$} & \multicolumn{4}{|c|}{ Level III Model } & \multicolumn{4}{|c|}{ Level IV Model } \\
\hline & Min & Max & Mean & SD & Min & Max & Mean & SD \\
\hline 12 & $-25.68 \%$ & $50.87 \%$ & $5.47 \%$ & $10.94 \%$ & $-23.67 \%$ & $84.56 \%$ & $5.74 \%$ & $12.95 \%$ \\
\hline 36 & $-34.41 \%$ & $116.80 \%$ & $18.63 \%$ & $22.46 \%$ & $-31.37 \%$ & $138.95 \%$ & $19.52 \%$ & $25.06 \%$ \\
\hline 120 & $-36.25 \%$ & $371.83 \%$ & $71.95 \%$ & $58.46 \%$ & $-54.64 \%$ & $436.30 \%$ & $80.62 \%$ & $70.35 \%$ \\
\hline
\end{tabular}

Source: own elaboration.

That is, this is evidence of the high risk to which the RPPSs would be exposed when implementing these allocations. The same is true for the level IV restricted model.

However, the free model has probabilities of obtaining negative returns equal to $15.3 \%, 3.8 \%$, and $0.0 \%$, at the end of the $12-, 36-$, and 120 -month period, respectively. This is always much lower than the values presented for restricted models III and IV. This is expected, since the current investment limits imposed on RPPSs end up also generating greater volatility in results.

Table 7 shows the statistics and the magnitudes of the returns resulting from the application of the optimal allocations in the scenarios over time. This analysis is interesting because it indicates the dimension of the stress scenario to which the portfolios would be exposed. For example, for the level III and IV models, there were situations in which they could generate strongly negative returns, evidencing the possibility of the RPPS presenting a significant reduction in equity.

As for the expected returns from the portfolios, it should be noted that the longer the horizon is, the greater the accumulated return must be, as well as the associated risk measure. It is interesting to note that the standard deviation in the level IV model - a more flexible portfolio - is always smaller than its equivalent for level III. On the other hand, the free model presents expected returns very similar to the level III and IV models with legal restrictions, both in the short and long terms. However, its great advantage over the others is the level of risk to which it is exposed: in addition to presenting a lower magnitude of negative results, the standard deviations are approximately half those of the restricted models.

With the presented results, and under the current economic scenario of a significant reduction in real interest rates provided by fixed income assets, there is a great need to revise the current legislation regarding the investment limits of RPPSs. In addition to not enabling the achievement of actuarial targets in the case of RPPSs that do not have any level of governance (restricted model), nor those that have levels I and II, nor even those classified as levels III and IV, the risk of entities failing to achieve short-term actuarial goals is high. This implies several negative accounting and economic consequences for those insured by these entities, which may not have covered expectations of future payments of benefits, precisely due to the entities not being able to sufficiently monetize their assets.

\section{FINAL REMARKS}

The drastic change in the structure of the interest rate curve that occurred recently in Brazil had a significant impact on RPPS investment portfolios. By implementing an ALM model, via a nonlinear programming problem, it was possible to empirically assess the ability of RPPSs to achieve the actuarial target of $6 \%$ p.a. in real interest. The results show that only the RPPSs classified as governance levels III and IV would be able to build portfolios with the expected returns capable of achieving the actuarial target of $6 \%$ p.a. However, it was only possible to achieve this at the limit of the efficient frontier, where the risk is as high as possible. The risk exposure of these portfolios is extremely high, which may expose entities to situations in which there is a high probability of equity reductions, which could generate or aggravate actuarial deficits.

The results obtained show that, under this new economic and financial scenario, the current RPPS investment limits do not offer satisfactory conditions for building sufficiently diversified investment portfolios with returns capable of achieving - and exceeding - the current actuarial goals. Thus, there is evidence that it is necessary for the appropriate regulators and autarchies to revise Res. CMN 3,922/2010 in order to increase the investment limits for the risky asset classes. On the other hand, it is essential to adopt good practices, policies, and processes that aim to raise RPPS governance, because the higher the level of governance is, the greater the chances 
of building efficient portfolios capable of achieving the actuarial goals.

Finally, this work should not be understood as a wholehearted defense of leveraging investment funds, but rather be used to understand the economic and social context that serves this type of institution. RPPSs are pension systems of federal entities set up to manage the granting of social security benefits to provide income to elderly civil servants when they retire. As they are entities that do not have profit as their primary objective, all the consequences of poor financial performance fall directly on the participants. Thus, only three possibilities are viable: either (i) the contribution rate of active participants rises; or (ii) retirees have their benefits reduced (by a nominal reduction in the amount of benefits, or by a contribution in the inactive phase); or even (iii) the sponsor - the public treasury of the federative entity - must bear the loss, redirecting public funds from other areas that have a higher priority for society. There would be no other way out.

\section{Notes}

${ }^{i}$ A comprehensive article on the subject can be found at: https://www.valor.com.br/financas/5684331/cvm-apertacerco-regimes-de-previdencia-dos-estados $>$. Accessed on April 19 of 2019.

ii Duration is the first-order derivative of the present value as a function of the interest rate variable. It is an indicator used to measure the sensitivity of the value of a security to changes in interest rates in the market.

iii Convexity is an indicator of the curvature of the present value as a function of the interest rate. It is obtained by the second-order derivative of the present value in relation to changes in the interest rate, divided by the present value.

iv Mark-to-market (MtM) is the current fair value of one or more future values and is calculated by discounting the flow of future values at market interest rates.

${ }^{v}$ Private Equity is an alternative investment class that invests in companies not listed on a public exchange. PE is composed of funds (FIP) and investors that invest directly in private companies or that are involved in acquisitions of public companies. Institutional and retail investors provide capital for PE funds, and this capital can be used to finance growth, invest in new technologies, make acquisitions, expand working capital, and strengthen and solidify a balance sheet.

\section{REFERENCES}

Andongwisye, J., Torbjörn, L., Singull, M., \& Mushi, A. (2018). Asset liability management for Tanzania pension funds by stochastic programming. Afrika Statistika, 13(3), 1733-1758. doi:10.16929/as/1733.13.

Cho, W. N. (2008). Robust porffolio optimization using conditional value at risk. London, UK: Imperial College London.

DATAPREV (Ed.) (2017). Anuário estatístico da previdência social: 2017, 24. Recuperado de http://sa.previdencia.gov. br/site/2019/04/AEPS-2017-abril.pdf

Dempster, M. A. H., Germano, M., Medova, E. A., \& Villaverde, M. (2003). Global asset liability management. British Actuarial Journal, 9(01), 137-195. doi: 10.1017/ S1357321700004153

Drijver, S. J., Haneveld, W. K., \& van der Vlerk, M. H. (2002). ALM model for pension funds: numerical results for a prototype model. (SOM Research Reports; No. A44). University of Groningen, SOM

Dutta, G., Rao, H. V., Basu, S., \& Tiwari, M. K. (2019). Asset liability management model with decision support system for life insurance companies: Computational results. Computers and Industrial Engineering, 128, 985998.doi:10.1016/j.cie.2018.06.033

Ferstl, R., \& Weissensteiner, A. (2011). Asset-liability management under time-varying investment opportunities. Journal of Banking and Finance, 35(1), 182-192. doi:10.1016/j.jbankfin.2010.07.028

Geyer, A., \& Ziemba, W. T. (2008). The innovest Austrian pension fund financial planning model InnoALM. Operations Research, 56(4), 797-810. doi:10.1287/opre.1080.0564

Hirsa, A., \& Neftci, S. N. (Ed.) (2013). An Introduction to the mathematics of financial derivatives (3rd ed.). London: Academic Press.

Hosseinzadeh, M. M., \& Consigli, G. (2017). Optimal asset-liability management for defined benefit pension fund under stochastic correlation. (Thesis of Doctor). Universitá Degli Studi di Bergamo, Bergamo, Itália. 
Hurtado, N. H. (2008). Análise de metodologias de gestão de ativos e passivos de planos de beneficio definido em fundos de pensão: Uma abordagem financeiro-atuarial (Tese de Doutorado). Universidade Federal do Rio de Janeiro UFRJ, Rio de Janeiro, RJ, Brasil.

Kouwenberg, R. (2001). Scenario generation and stochastic programming models for asset liability management. European Journal of Operational Research, 134(2), 279-292. doi:10.1016/S0377-2217(00)00261-7

Krokhmal, P., Uryasev, T., \& Palmquist, J. (2001). Portfolio optimization with conditional value-at-risk objective and constraints. The Journal of Risk, 4(2), 4368. doi.:10.21314/JOR.2002.057

Lauria, D., \& Consigli, G. (2017). A defined benefit pension fund ALM model through multistage stochastic programming. International Journal of Finance and Managerial Accounting, 2(7), 1-10.

Leibowitz, M. L., Fabozzi, F. J., \& Sharpe, W. F. (1992). Investing: the collected works of Martin L. Leibowitz. Chicago: Probus Publishing.

Minardi, A. M. A. F., Bortoluzzo, A., \& Moreira, L. do. A. (2017). Private equity and venture capital growth and performance in emerging markets. SSRN Electronic Journal, 1-21. doi:10.2139/ssrn.2894543

Minardi, A., \& Moreira, L. do A. (2014). Determinantes do retorno de private equity e venture capital no Brasil (Trabalho de conclusão de curso). Instituto de Ensino e Pesquisa - INSPER, São Paulo, SP, Brasil.

Oliveira, A. D. de. (2018). Essays on Multistage Stochastic Programming applied to Asset Liability Management (Tese de Doutorado). Universidade Federal do Rio Grande do SUL - UFRGS. Porto Alegre, RS, Brasil.

Oliveira, A. D. de, Filomena, T. P., Perlin, M. S., Lejeune, M., \& Macedo, G. R. de (2017). A multistage stochastic programming asset-liability management model: An application to the Brazilian pension fund industry. Optimization and Engineering, 18(2), 349-368. doi:10.1007/s11081-016-9316-3

Rao, H. V., Dutta, G., \& Basu, S. (2018). New asset liability management model with decision support system for life insurance companies: Interface design issues for database and mathematical models. International Journal of Revenue Management, 10(3-4), 259-289. doi.: 10.1504/ IJRM.2018.096319

Ribeiro, G. X. K. (2015). Asset liability management em um plano aberto de previdência complementar tradicional (Dissertação). Instituto Nacional de Matemática Pura e Aplicada - IMPA. Rio de Janeiro, RJ, Brasil. Recuperado de file://C:/Users/Administrador/Desktop/2\%20 ano/1\%20semestre/Reconceitua\%C3\%A7\%C3\%A3o/ documento.pdf

Resoluçáo CMN no3922, de 25 de novembro de 2010. Dispóe sobre as aplicaçôes dos recursos dos regimes próprios de previdência social instituídos pela União, Estados, Distrito Federal e Municípios. Recuperado de https://www.bcb.gov.br/estabilidadefinanceira/exibenorm ativo?tipo=Resolu\%C3\%A7\%C3\%A3o\&numero=3922

Resolução CMV n4604, de 19 outubro de 2017. Altera a Resolução no 3.922, de 25 de novembro de 2010, que dispóe sobre as aplicaçóes dos recursos dos regimes próprios de previdência social instituídos pela União, Estados, Distrito Federal e Municípios. Recuperado https://www. bcb.gov.br/estabilidadefinanceira/exibenormativo?tipo $=\mathrm{R}$ esolu\%C3\%A7\%C3\%A3o\&numero=4604

Resoluçáo CMV no4695, de 25 de novembro de 2018. Altera a Resoluçáo no 3.922, de 25 de novembro de 2010, que dispóe sobre as aplicaçôes dos recursos dos regimes próprios de previdência social instituídos pela Uniáo, Estados, Distrito Federal e Municípios e a Resolução no 4.661, de 25 de maio de 2018, que dispóe sobre as diretrizes de aplicaçáo dos recursos garantidores dos planos administrados pelas entidades fechadas de previdência complementar. Recuperado de http://sa.previdencia.gov. br/site/2018/12/Resolucao-No-4695_2018.pdf

Rockafellar, R. T., \& Uryasev, S. (2000). Optimization of conditional value-at-risk. The Journal of Risk, 2(3), 21-41. doi:10.21314/JOR.2000.038

Ryan, R. J. (2013). The evolution of asset/liability management. Research Foundation Literature Review, 8(2) doi: 10.2470/rflr.v8.n2.1

Saad, N., \& Ribeiro, C. O. (2004). Modelos determinísticos de gestão de ativo/passivo: uma aplicação no Brasil. Revista 
Contabilidade \& Finanças, (34), 50-62. doi:10.1590/ S1519-70772004000100004

Saad, N. S., \& Ribeiro, C. de O. (2006). Um modelo de gestão de ativo/passivo: aplicação para fundos de benefício definido com ativos de fluxo incerto. Revista Contabilidade \& Finanças, 17(spe2), 75-87. doi:10.1590/s1519-70772006000500006

Toukourou, Y. A. F., \& Dufresne, F. (2018). On Integrated chance constraints in ALM for pensions funds. ASTIN Bulletin, 48(02), 571- 609. doi:10.1017/asb.2017.49
Valladão, D. M. (2008). Alocaçâa ótima e medida de risco de um ALM para fundo de pensão via programação estocástica multi-estágio e bootstrap(Dissertação de Mestrado). Pontificia Universidade Católica do Rio de Janeiro - PUC. Rio de Janeiro, RJ, Brasil. Recuperado de https://www. maxwell.vrac.puc-rio.br/colecao.php?strSecao=resultad o\&nrSeq=12253@1

Ziemba, W. T. (2003). The stochastic programming approach to asset, liability, and wealth management. United States: AIMR Publisher.

\section{Conflicts of interest:}

The authors have no conflict of interest to declare.

\section{Copyrights:}

RBGN owns the copyrights of this published content.

\section{Plagiarism analysis:}

RBGN performs plagiarism analysis on all its articles at the time of submission and after approval of the manuscript using the iThenticate tool.

\section{Authors:}

1. Alexandre Teixeira Damasceno, BSc. in Actuarial Science, Universidade de São Paulo, São Paulo, Brazil.

E-mail: aledamac@gmail.com

2. João Vinícius de França Carvalho, PhD in Statistics, Universidade de São Paulo, São Paulo, Brazil.

E-mail: jvfcarvalho@usp.br

\section{Authors' Contributions:}

$\mathbf{1}^{\text {st }}$ author: definition of research problem; development of hypotheses or research questions (empirical studies); definition of methodological procedures; data collection; literature review; statistical analysis; analysis and interpretation of data; critical revision of the manuscript; manuscript writing.

$2^{\text {nd }}$ author: definition of research problem; development of hypotheses or research questions (empirical studies); definition of methodological procedures; data collection; literature review; statistical analysis; analysis and interpretation of data; critical revision of the manuscript; manuscript writing. 